\title{
Determination of ozone distribution in fish cold storage dedicated plasma ozone technology
}

\author{
Intan Zahar ${ }^{1 . *}$, Yuliani Yuliani ${ }^{1,2}$, Eko Yulianto ${ }^{1}$, Meliza Meliza ${ }^{1,2}$, Ade Ika Susan ${ }^{1}$, Sumariyah Sumariyah ${ }^{1}$, and \\ Muhammad Nur ${ }^{1}$ \\ ${ }^{1}$ Diponegoro University, Center for Plasma Ressearch, Faculty of Science and Mathematics, Semarang, Indonesia \\ ${ }^{2}$ Diponegoro University, Physics Department, Faculty of Science and Mathematics, Semarang, Indonesia \\ ${ }^{3}$ Diponegoro University, Fishery Products Technology Department, Faculty of Fisheries and Marine Sciences, Semarang, Indonesia
}

\begin{abstract}
Research on the distribution of ozone in a cold storage has been done. This cold storage is equipped with an ozone piping system. Ozone inserts to the cold storage was generated by dielectric barrier discharge plasma. The reactor is made of two stainless steel mesh wire cylindrical electrodes and a barried by a pyrex tube. The pipes are hollowed so that ozone can be distributed into cold storage. The distribution of ozone in cold storage is determined by placing a petri dish in twenty-four different points. Ozone that inserted to storage (10 cubic meters) with a capacity of 40 grams/hour. The inserting of ozone into cold storage was done with four different lengths of time wich are 30, 60, 90, and 120 minutes. Ozone distribution in storage was almost the same at each measurement points. The most influential in the distribution is the time. We found that the distribution of ozone into storage with average ozone concentration of $4.3,6.3,4.6$, and $4.0 \mathrm{ppm}$ with time $30,60,90,120$ minutes respectively. Futhermore, we also dissolve the ozone into the water in the tank in the same storage with temperature $(2-8)^{0} \mathrm{C}$. We found that the concentration of dissolved ozone in the water without samples was always greater than that of the existing fish and shrimp samples, with various dissolution times between (30-120) minutes at 30 minutes intervals. Cold storage dedicated ozone was used to store fish used to store tuna, milkfish and shrimp. With ozone immersion of fish in ozone-soluble water can maintain fish quality for 16 days.
\end{abstract}

\section{Introduction}

Ozone consists of three oxygen atoms that have the chemical formula O3. The ozone molecule is unstable. Ozone is a strong oxidizing agent as an antimicrobial, as a bactericidal and disinfectant that can be used to ensure microbiological safety in food and affect fish preservation [1-3]. Ozone can be produced by using two electrodes, while the factors affecting ozone formation are voltage, dielectric material, pressure, congruency of the plasma and gas reactor systems included in the plasma reactor [4]. Ozone has some advantages that can influenced membrane glycoproteins, glycopids, enzymes, can maintain protein and DNA [5]. Then ozone can decompose quickly to produce oxygen and leave no residue in food [6]. Various countries have allowed the use of Ozone for the treatment of food with certain standards The US Food and Drug Administration (FDA) has approved ozone treatment for food storage in gas and liquid phases [1-2, 4-5]

One technique to produce ozone is to use Dielectric Barrier Discharge (DBD) by utilizing high voltage $[7,8]$. DHF is an ozone generator reactor by utilizing plasma discharges which is generated in the gap between the two electrodes ie the wire electrode as the inner electrode and the outer electrode as the passive electrode using the aluminum sheet with a pyrex glass tube as a dielectric material in order to avoid arc discharges. When free air or pure oxygen at atmospheric pressure is passed through the gap between the two electrodes there will be ionization process and produce ozone $[9,10]$. The use of ozone in keeping the shelf life in food has been widely practiced. Fish is a promising food preservation technology. Some researchers have used ozone to maintain fish quality, [11] has utilized ozone to improve the safety and quality of salmon. [12] Conducted an ozone study to maintain the quality of amino acids in fish. Based on the research it is necessary to further research in the form of other factors that affect the quality of fish and the most effective way to maintain freshness quality of fish on a large scale using cold storage. In this paper the researcher tries to conduct research of fish preservation using tuna fish, milkfish and shrimp that represents the type of sea water fish, freshwater and crustacea in cold storage to know the physical parameters related to storage of fish in Cold Storage which is run by Ozone Generator such as optimum time of drainage ozone, dissolved ozone concentration, and air ozone concentration.

* Corresponding author: intan.zahar@st.fisika.undip.ac.id 


\section{Materials and Methods}

Figure 1 shows a set of research tools. In this study used cold storage (Dipo Technology Company, Semarang) size $2 \times 2 \times 2.5 \mathrm{~m} 3$ or with volume of $10 \mathrm{~m}^{3}$. Colt Storge is used as a storage place for fish. In cold storage there is a rack that is used as a place of fish treatment. Cold Storage is equipped with Ozone Generator (D'Ozone, Dipo Technology Company, Semarang) which is generated using Dielectric Barrier Discharge with reactor cylindrical configuration that made by using two stainless steel mesh wire electrodes and a barrier by a pyrex tube. Cold storage used a chiller with temperature of $2^{0}-8^{0} \mathrm{C}$.

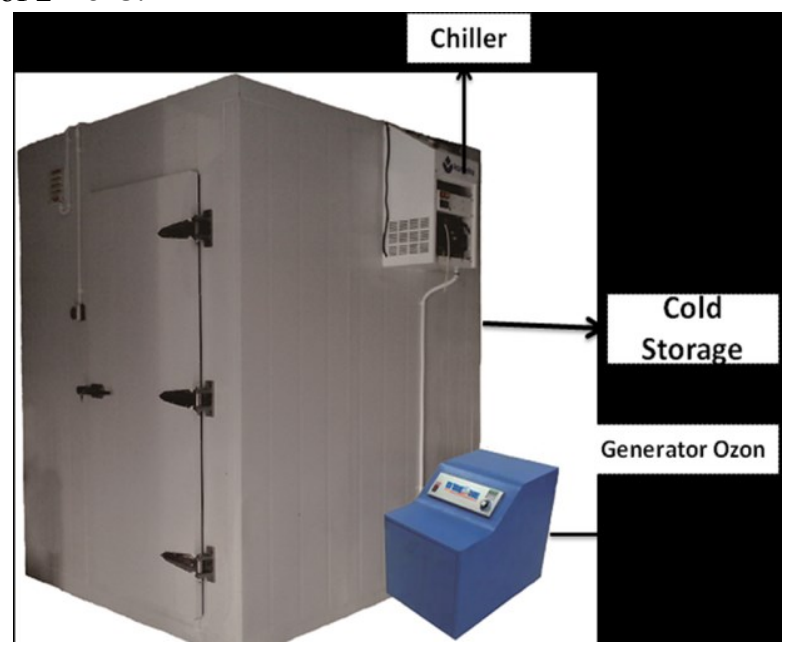

Fig. 1. Cold storage, Ozone generator and Chiller

Figure 2 shows the measurement of air ozone concentration in Cold Storage generated from ozone generator measured using titration method using KI solution (Kimia Farma Company, Jakarta) with 0.2 molar concentration and $\mathrm{Na}_{2} \mathrm{~S}_{2} \mathrm{O}_{3}$ solution (CV Indrasari, Semarang) with concentration 0.4 molar. Measurement of air ozone concentration was done by placing a petri dish in fill with $50 \mathrm{ml}$ of KI solution at each corner of the rack (Rack I, II and III with angle a - g). Measurement of ozone concentration was done with variation of time ie for 30 minutes, 60 minutes, 90 minutes and 120 minutes. The dissolved ozone concentration was measured using a test kit with variations of time for 30 minutes, 60 minutes, 90 minutes and 120 minutes. Samples used in this study were tuna fish, milkfish and shrimp. The distribution of ozone in cold storage is determined by the titration method. Ozone flowed in cold storage with a volume of $10 \mathrm{~m}^{3}$ with a temperature of $2-8^{0} \mathrm{C}$. In Cold Storage there is a fish storage rack where each corner of the shelf is given a petri dish containing the KI solution. Ozone measurements were performed by titration method with variations of time $30,60,90$ and 120 minutes.

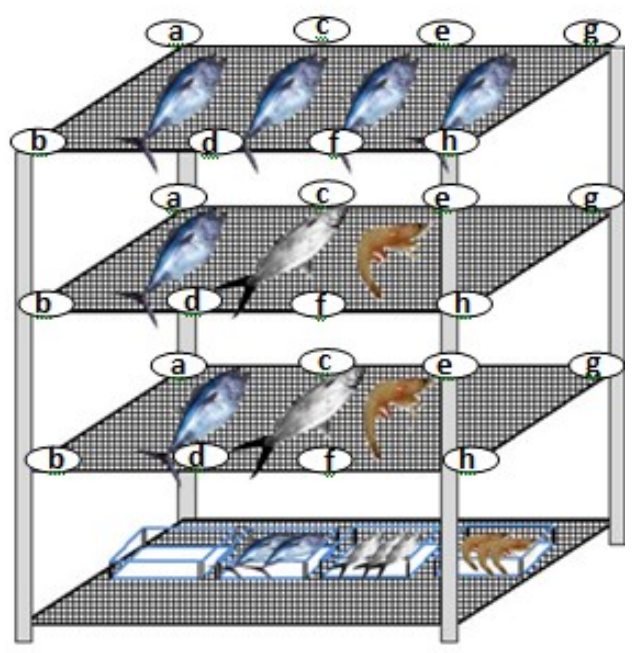

Fig. 2. Position measurement of ozone concentration in storage.

In storage there are three types of treatments: the sample is immersed in ozone dissolved water. The sample was washed with water of the ozone and the sample was just placed on top. All in storage with temperature between $2-8^{0} \mathrm{C}$. The samples used in this research are tunafish, milkfish and shrimp.

\section{Results and Discussion}

The main objective of this study was to conduct further studies to optimize ozone production in Cold Storage and obtain optimal time for ozone gas and ozone depletion in Cold Storage resulting in effective dosage of ozone without causing significant changes in fish. This research is also expected to get Standard Operation of Fish Treatment

\subsection{Ozone Generator Characteristics}

The graph shown in Figure 3 is the ozone concentration as a function of the input voltage of the generator. The data taken in this research is the relationship of data voltage $(\mathrm{V})$ with the concentration of ozone generated based on voltage variation. For the equations look for the resulting ozone concentration using the following equation:

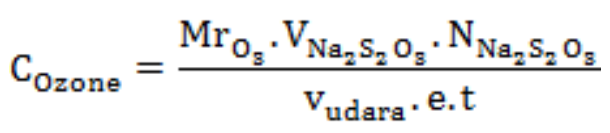

Where $\mathrm{Mr}_{\mathrm{O}_{3}}$ is the relative molecular mass of

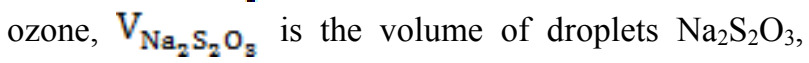

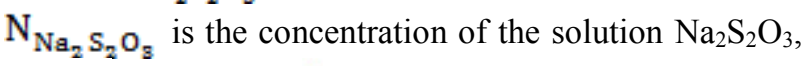
$\mathrm{v}_{\text {udara }}$ is flowrate, $\mathrm{e}$ is a constant that is 2 times the mass of the electron and is the time of dissolution of ozone into the KI solution [13]. It appears that the ozone concentration is close to the 2 nd order polynomial 
$\left(\mathrm{C} \sim \mathrm{V}^{2}\right)$ as a function of the voltage. The greater the voltage then the greater the ozone concentration.

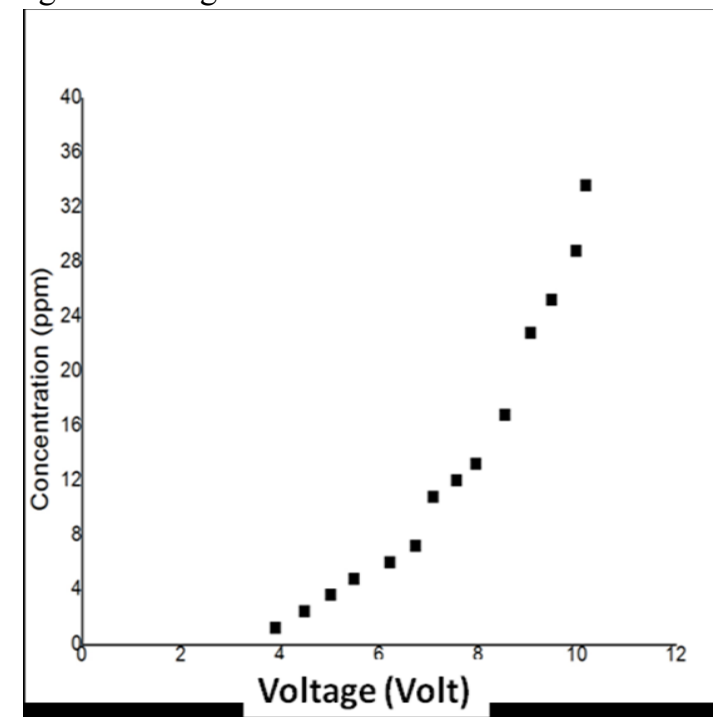

Fig. 3. Ozone Concentration as Function of Voltage.

\subsection{Ozone Concentration in Storage}

Figure 4 shows the concentration of zones as a function of ozone flow time into storage. Charging is done at a position set on the shelf. The displayed value is the average value.

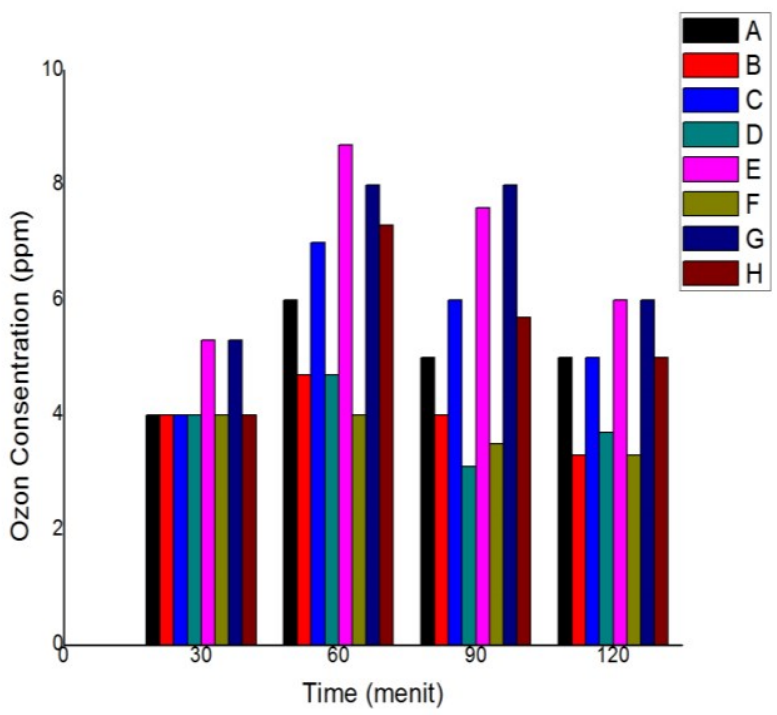

Fig. 4. Concentration ozone in Storage at each position (A, $\mathrm{B}, \mathrm{C}, \mathrm{D}, \mathrm{E}, \mathrm{F}, \mathrm{G}, \mathrm{H})$ as function of time.

From the bar rods presented in the figure, the maximum ozone concentration in Cold Storage is obtained with a flow time of 60 minutes. The average concentration for all positions is $6.2 \mathrm{ppm}$. We use this as a standard for fish processing. Ozone flow in Cold Storage can hold the shelf life of milkfish for 6 days of storage, with a TPC value of 4.7 x $106 \mathrm{CFU} /$ gr. [14] suggest that ozone treated fresh fish show better sensor aspects than those not treated.

\subsection{Disolved Ozone in Water for Treatment}

Ozone is injected in a box containing water placed in storage, including a 1: $1(\mathrm{w} / \mathrm{v})$ sample for 30, 60, 90 and $120 \mathrm{~min}$. The graphic results shown in Fig. 5 indicate that the concentration of ozone dissolved in unsampled water is always greater than the sample of fish and shrimp. The dissolution times of ozone in water between (30-120) minutes with interval time was 30 minutes.

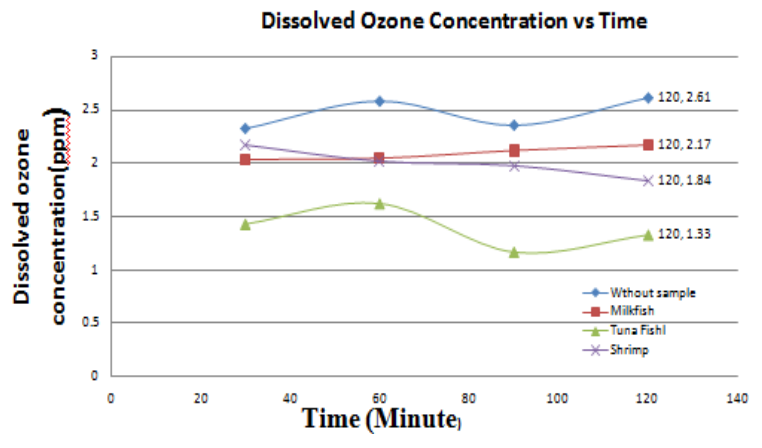

Fig. 5. The concentration of ozone dissolved.

The distribution of ozone dissolved in storage is almost the same in each sample which is about $2 \mathrm{ppm}$. By injecting ozone in water can maintain the freshness of the fish for 16 days. According to [15] the combination of ozone with slurry ice may increase the shelf life of fish compared with using ice slurry.

\section{Conclusions}

Ozone generators with Dielectric Barrier Discharge Plasma Technology have been applied to maintain the shelf life of fish. The concentration of dissolved ozone in unsampled water is always greater than the existing fish and shrimp samples, with different dissolution times between (30-120) minutes at 30 minute intervals. Special ozone storage with ozone distribution of $6 \mathrm{ppm}$ is used to store and enhance the quality of tuna, milkfish and shrimp. With ozone immersion fish in water dissolved in ozone can maintain the quality of fish for 16 days with ozone concentration of about $2 \mathrm{ppm}$, so a good standard to maintain the shelf life of the fish is by immersion technique by injecting ozone into water stored in Cold Storage with temperature $2^{0}-8^{0} \mathrm{C}$

\section{References}

1. Khadre, M.A., Yousef, A.E., Kim, J.G, J. Food Sci. 66, 9 (2001)

2. Kim, J.G., Yousef, A.E., Dave, S, J. Food Protch. 62, 9 (1999)

3. Hobbs, G. Food Sci. Techno. Today. 5, 166173 (1991)

4. Changquan Wang, Guixin Zhang and Xinxin Wang., 86, 960964 (2012) 
5. Cullen, P.J. Tiwari, B.K. O'Donnell, C.P. and Muthukumarappan, K, Trends in Food Science \& Technology. 20, 125136 (2009)

6. Tiwari, B.K. Brennan, C.S. Curran, T. Gallagher, E. Cullen, P.J. and O' Donnell, C.P. J. Cereal Sci. 5, 248255 (2010)

7. Boonduang, S. Limsuwan, S. Kongsri, W. and Limsuwan, P, Pro. Engi. 32, 936942 (2012)

8. Yao, S. Wu, Z. Han, J. Tang, X. Jiang, B. Lu, H. Yamamoto, S. and Kodama, S, J. Electrostatics. 75. 3542 (2015)

9. Nur, M. Resti, M. Arianto, F. Muhlisin, Z. Teke, S. Susan A.I. ISTMET, 2729 (2014)

10. Bechaux, J. John Wiley and Sons: New York. (1979)

11. Crowe, M.K. Skonberg, D. Bushway, A. Baxter, S. J. Food Control. 25, 464468 (2012)

12. Teke, Sosiawati. Skripsi, FSM, Universitas Diponegoro, Semarang. (2014)

13. Suraidin, Nur, M., Gunawan, and Susan, I.A. J. of Physics. 776, 16 (2016)

14. Silva da, M.V. Gibbs, P.A. \& Kirby, R. M, J. Applied Mic. 84, 802810 (1998)

15. Compos, C.A. Losada, V. Rodriguez, O. Aubourge, S.P. Velazquez, J.B. J. Food Chemistry. 97, 223230 (2006) 